\title{
LUPUS SCIENCE\& MEDICINE \\ Off-label use of rituximab for systemic lupus erythematosus in Europe
}

Monica Rydén-Aulin, ${ }^{1}$ Dimitrios Boumpas, ${ }^{2}$ Irene Bultink, ${ }^{3}$ Jose Luis Callejas Rubio, ${ }^{4}$ Luis Caminal-Montero, ${ }^{5}$ Antoni Castro, ${ }^{6}$ Agustín Colodro Ruiz, ${ }^{7}$ Andrea Doria, ${ }^{8}$ Thomas Dörner, ${ }^{9}$ Cristina Gonzalez-Echavarri, ${ }^{10}$ Elisa Gremese, ${ }^{11}$ Frederic A Houssiau, ${ }^{12}$ Tom Huizinga, ${ }^{13}$ Murat Inanç, ${ }^{14}$ David Isenberg, ${ }^{15}$ Annamaria luliano, ${ }^{16}$ Søren Jacobsen, ${ }^{17}$ Juan Jimenéz-Alonso, ${ }^{18}$ Lászlo Kovács, ${ }^{19}$ Xavier Mariette, ${ }^{20}$ Marta Mosca, ${ }^{21}$ Ola Nived, ${ }^{22}$ Joaquim Oristrell, ${ }^{23}$ Manuel Ramos-Casals, ${ }^{24}$ Javier Rascón, ${ }^{25}$ Guillermo Ruiz-Irastorza, ${ }^{10}$ Luis Sáez-Comet, ${ }^{26}$ Gonzalo Salvador Cervelló, ${ }^{27}$ Gian Domenico Sebastiani, ${ }^{28}$ Danilo Squatrito, ${ }^{29}$ Gabriella Szücs, ${ }^{30}$ Alexandre Voskuyl, ${ }^{31}$ Ronald van Vollenhoven ${ }^{1,32,33}$

To cite: Rydén-Aulin M, Boumpas D, Bultink I, et al. Off-label use of rituximab for systemic lupus erythematosus in Europe. Lupus Science \& Medicine 2016;3:e000163. doi:10.1136/lupus-2016000163

Received 26 April 2016 Revised 22 June 2016 Accepted 31 July 2016

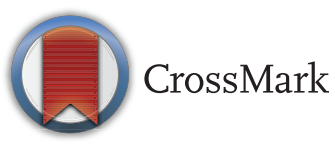

For numbered affiliations see end of article.

Correspondence to Professor Ronald F van Vollenhoven; ronald.van. vollenhoven@ki.se,

r.f.vanvollenhoven@amc.nl

\section{ABSTRACT}

Objectives: Rituximab (RTX) is a biological treatment used off-label in patients with systemic lupus erythematosus (SLE). This survey aimed to investigate the off-label use of RTX in Europe and compare the characteristics of patients receiving RTX with those receiving conventional therapy.

Methods: Data on patients with SLE receiving RTX were taken from the International Registry for Biologics in SLE retrospective registry and complemented with data on patients with SLE treated with conventional therapy. For nationwide estimates of RTX use in patients with SLE, investigators were asked to provide data through case report forms (CRFs). Countries for which no data were submitted through CRFs, published literature and/or personal communication were used, and for European countries where no data were available, estimates were made on the assumption of similarities with neighbouring countries. Results: The estimated off-label use of RTX in Europe was $0.5 \%-1.5 \%$ of all patients with SLE. In comparison with patients with SLE on conventional therapy, patients treated with RTX had longer disease duration, higher disease activity and were more often treated with immunosuppressives. The most frequent organ manifestations for which either RTX or conventional therapy was initiated were lupus nephritis followed by musculoskeletal and haematological. The reason for treatment was, besides disease control, corticosteroid-sparing for patients treated with conventional therapy.

Conclusions: RTX use for SLE in Europe is restrictive and appears to be used as a last resort in patients for whom other reasonable options have been exhausted.

\section{INTRODUCTION}

Systemic lupus erythematosus (SLE) is an inflammatory autoimmune disease with a wide spectrum of clinical manifestations. This diversity is a reflection of the dysregulation of several components of the immune system, resulting in B-cell hyperactivity and production of autoantibodies. ${ }^{\text {P }}$

Most therapies for SLE are off-label. Thus, conventional immunosuppressants (IS) such as azathioprine, methotrexate and mycophenolate mofetil are widely used, but are not approved for this disease. Not even the 'gold standard' treatment for severe lupus and lupus nephritis (LN), cyclophosphamide (CYX), has been approved by either the Food and Drug Administration (FDA) or European Medicines Agency (EMA), although in some countries the indications may be listed in the prescribing information. In addition, these therapies can be associated with severe adverse effects, and few patients reach durable full remission. ${ }^{2}$

The development of biological therapies has dramatically changed the treatment for inflammatory autoimmune diseases such as rheumatoid arthritis (RA), Crohn's disease, psoriasis and multiple sclerosis. Therefore, biological therapies may offer new ways of treating SLE. As a consequence, experimental use of biologics targeting B-cell activity has escalated during the past decade, in particular rituximab (RTX) (MabThera, Rituxan) and belimumab (Benlysta).

Belimumab is a B-cell directed anticytokine agent, leading to downregulation of B-cell activity and hence lower levels of Ig, including autoantibodies. Positive results with belimumab led to approval for treatment of SLE by both EMA and FDA. ${ }^{34}$ 
RTX is an antibody directed to CD20, a B-cell surface marker, which has been shown to be effective in depleting $\mathrm{B}$ cells in vivo and is approved for treatment of B-cell malignancies and for autoimmune diseases such as $\mathrm{RA}^{5}$ and ANCA-associated vasculitis. ${ }^{6}{ }^{7}$ Over the past several years, off-label use of RTX in SLE has emerged as one of the biological therapies used in clinically challenging cases. Two controlled trials with RTX performed in the USA failed to meet their primary endpoints when RTX was added to conventional therapy as compared with the addition of placebo to the same. ${ }^{8}$ The patients in the trials had active SLE but were not required to have failed prior conventional therapy. However, in the renal lupus trial, many exploratory endpoints at 78 weeks were met, both serological and clinical. Multiple, mostly uncontrolled observational, studies have suggested that RTX provides significant benefits when given to patients with severe or refractory SLE, sometimes in conjunction with CYX. ${ }^{10-20}$ Thus, as RTX is not approved for treatment of SLE, these reports raised the question of how widely RTX is used in SLE and for what specific indications.

The use of registries, where data are collected systematically on well-characterised patient populations treated with specific agents, is an important source of information about real-life efficacy and safety. The European registries, ARTIS (Sweden), ${ }^{21}$ BSRBR (UK), ${ }^{22}$ DAN-BIO (Denmark $^{23}$ and GRAID (Germany), ${ }^{24}$ just to name a few, have contributed to the knowledge of both positive and negative aspects of studied agents in the treatment of rheumatic diseases. Therefore, we have initiated the International Registry for Biologics In SLE (IRBIS), in which data are collected retrospectively and prospectively on patients with lupus treated with biologics. The IRBIS registry was approved by the Systemic Lupus International Collaborating Clinics (SLICC) group in 2009.

The objective of this study was to investigate the extent of off-label use of RTX in SLE in Europe, and for what specific indications. It is a compilation of data from the European dataset in IRBIS, published material and data provided by participating investigators.

\section{METHODS}

\section{Data collection}

We used data submitted by the European contributors to the IRBIS registry on RTX-treated patients (demographic, disease-specific and treatment). Contributors were asked to provide additional information on the number of patients with SLE at their centres, on patients with SLE within their region and estimates for the whole country in specific case report forms (CRFs). As a control, data were also collected on patients who were started on conventional IS therapy not including corticosteroids and antimalarials. Any patient on RTX or conventional treatment from 2010 to 2013 was allowed for inclusion.

Data from the CRFs were complemented with published data and by personal communication with participating investigators. Twenty-nine centres from 12 countries participated (table 1).

The hierarchy of data was: (1) data from the participating investigators' registries; (2) data from CRFs; (3) data from published studies; (4) data provided through direct contact with participating physicians.

For countries not represented in the IRBIS collaboration, and where therefore no data were available, estimates were made on the assumption of similarities with neighbouring countries.

\section{Patients}

All patients fulfilled the revised and/or updated American College of Rheumatology (ACR) criteria. Ethical approval for the study was obtained in countries where this was required and all patients gave their oral and/or written consent.

The anonymity of participating patients was maintained in accordance with Good Clinical Practice (GCP) guidelines. For data collection and management purposes, patients were identified by a patient number only. Documents identifying the patient were not submitted to the registry centre.

\section{Statistics}

For the descriptive data, means and SDs were calculated. For comparisons between groups, unpaired t-test or Mann-Whitney U test was used for normally distributed and non-parametric data, respectively, using SPSS (no 21).

\section{RESULTS}

Estimates of number of patients with SLE and the use of RTX in Europe

Contributing centres and patient referrals

We inquired which patient subsets were seen at the participating centres and how these patients were referred

Table 1 Countries and centres that provided information for this study

\begin{tabular}{|c|c|c|}
\hline Country & $\begin{array}{l}\text { Sites/ } \\
\text { country }\end{array}$ & Site/region represented \\
\hline Belgium & 1 & Belgium \\
\hline Denmark & 1 & Copenhagen \\
\hline France & 1 & Paris \\
\hline Germany & 1 & Central Germany \\
\hline Greece & 1 & Crete \\
\hline Hungary & 1 & Southeast Hungary \\
\hline Italy & 4 & Tuscany (2), Veneto, Lazio \\
\hline Spain & 13 & $\begin{array}{l}\text { Bizkaia, Andalucia (2), } \\
\text { Madrid, Catalonia (3), } \\
\text { Balearic Islands, Asturias, } \\
\text { Jaen, Valencia, Zaragoza, } \\
\text { Granada }\end{array}$ \\
\hline Sweden & 2 & Stockholm, Lund \\
\hline $\begin{array}{l}\text { The } \\
\text { Netherlands }\end{array}$ & 2 & Leiden, Amsterdam \\
\hline Turkey & 1 & Istanbul \\
\hline UK & 1 & London \\
\hline
\end{tabular}


to the site. For most centres (17 out of 29 ), patients with SLE were seen from a well-defined region, or from the whole country, and referred to them by the primary physician.

Participating investigators were asked to provide information on the number of centres within their own region where patients with SLE were likely to be treated with RTX. Centres within the same region and with similar treatment strategies ranged from 1 to 20; only five centres responded that they were the sole centre where patients with SLE were treated with RTX in their region.

\section{Patients with SLE at each participating centre}

Most of the rheumatology (SLE) specialty centres represented in this study had 200-300 patients with SLE, of whom generally $<5 \%$ were treated with RTX, with some notable exceptions (table 2). It can be seen that there was a wide range in the proportion of patients treated with conventional therapies, and data provided from Spain and Italy, where there are several sites, showed clear regional variation.

\section{Estimates of patients with SLE and RTX use in 31 European countries}

To address the prevalence of SLE and the use of RTX in patients with SLE in Europe, participating centres were asked to provide data about the number of patients with SLE and the number of patients with SLE treated with RTX in their country. These data were complemented with the data from published medical journal articles and publicly available healthcare sources.

The prevalence of SLE in countries with contributing centres ranged from 1 to 13 per 10000 . For some of the

Table 2 Patients with SLE on different treatments at participating sites, sorted by country

\begin{tabular}{|c|c|c|c|}
\hline Country & $\begin{array}{l}\text { Patients } \\
\text { with } \\
\text { SLE }\end{array}$ & $\begin{array}{l}\text { Patients } \\
\text { with } \\
\text { SLE on } \\
\text { RTX (\%) }\end{array}$ & $\begin{array}{l}\text { Patients with SLE } \\
\text { on conventional } \\
\text { immunosuppressive } \\
\text { therapy (\%) }\end{array}$ \\
\hline Belgium* & 5000 & 1 & 30 \\
\hline Denmark & 250 & 2 & 50 \\
\hline France* & 22500 & $1.6 \dagger$ & - \\
\hline Germany & 325 & 4 & 92 \\
\hline Greece & 500 & 3 & - \\
\hline Hungary & 250 & 1 & 40 \\
\hline Italy & $200-400$ & $3-4$ & $20-62$ \\
\hline Spain & $5-900$ & $0-11$ & $19-70$ \\
\hline Sweden & $250-350$ & $4-20$ & $40-65$ \\
\hline The & 200-275 & $1-4$ & $20-25$ \\
\hline \multicolumn{4}{|c|}{ Netherlands } \\
\hline Turkey & 600 & 4 & 42 \\
\hline UK & 450 & 7 & 85 \\
\hline
\end{tabular}

${ }^{*}$ Figures are representative for the whole country.

†Derived from the number of patients (160) in the nationwide

Autoimmunity and Rituximab (AIR) registry, which represents about $50 \%$ of patients with SLE on RTX.

RTX, rituximab; SLE, systemic lupus erythematosus. countries, the distribution of ethnical groups within the country's population may account for higher prevalence in some regions, since people with Afro-Caribbean and Asian origins have been shown to have a higher SLE prevalence than Caucasians. ${ }^{25-27}$ Based on these data, we calculated that $0.6 \%-1.6 \%$ of patients with SLE were treated with RTX (table 3).

To get an estimate for the prevalence of SLE and RTX use in countries under the jurisdiction of the EMA, the remaining EU countries and the EFTA countries, Iceland, Liechtenstein and Norway, were included. For these countries, no data or information through personal communication are available. Instead, estimates were made on the assumption of similarities with neighbouring countries (table 3 ).

With a population of around 573 million, we estimated that the incidence of patients with SLE is roughly between 156000 and 269000 , giving an overall prevalence of 4.1-7.1/10 000, subject to significant nationwide and regional variabilities. Out of these patients, our analyses indicate that between $0.5 \%$ and $1.5 \%$ were treated with RTX at the time of data collection (table 3 ).

\section{Analysis of RTX-treated patients}

After estimation of the prevalence of SLE and RTX use in Europe, we wanted to investigate on what premises RTX is prescribed.

\section{Demographics of patients with SLE}

One hundred and three RTX-treated patients and 72 conventional IS-treated patients were included in this analysis, and their demographics are listed in table 4 . The majority (93\% and $91 \%$, respectively) was Caucasian, and smaller proportions were Latino/South African, Asian/Indian, Southeast Asian, African-American, AfroCaribbean or other (each $\leq 5 \%)$. Most patients were non-smokers. In both groups, most patients were female. Mean age was numerically higher in the RTX group.

\section{SLE disease characteristics}

Disease duration when RTX was initiated was 9.1 \pm 7.1 years, as compared with the significantly shorter duration for patients treated with conventional IS, 4.1 \pm 6.6 years (table 5 ).

The major organ manifestations leading to treatment for both groups were LN, musculoskeletal and haematological (table 5). Controlling the disease was significantly higher as the main reason for treatment in the RTX group, while steroid sparing (and disease control) was more prevalent in the control group (table 5).

Both SLE Disease Activity Index (SLEDAI) and SLICC-damage index (DI) were significantly higher at the start of treatment in the RTX group compared with conventional IS (table 5). SLEDAI was $12.2 \pm 7.1$ vs 9.4 \pm 7.0 and SLICC-DI was $1.6 \pm 3.4$ vs $0.6 \pm 1.0$. SLEDAI was significantly higher in $\mathrm{LN}$ than in non-LN patients, for both treatment groups. 
Table 3 Estimates of the overall number of patients with SLE, and patients on RTX, by country

\begin{tabular}{|c|c|c|c|c|c|}
\hline Country & Population & Patients with SLE * & $\begin{array}{l}\text { SLE/ } \\
10.000 \dagger\end{array}$ & $\begin{array}{l}\text { Patients with SLE } \\
\text { on RTX } \ddagger\end{array}$ & Reference§ \\
\hline Belgium & 10839905 & 5000 & 7.0 & $52(1.0 \%)$ & PC \\
\hline Denmark & 5511000 & 1000 & 2.7 & $10(1.0 \%)$ & $\mathrm{CRF}^{35}$ \\
\hline France & 61538322 & 22500 & 5.5 & $360(1.6 \%)$ & PC \\
\hline Germany & 82217837 & $5000-30000$ & $0.9-5.5$ & $150(0.5 \%-3.0 \%)$ & $\mathrm{CRF}^{36}$ \\
\hline Greece & 10760136 & $2800-7800$ & $4-11$ & $80-100(1.0 \%-3.5 \%)$ & $\mathrm{PC}^{3738}$ \\
\hline Hungary & 10045000 & $3000-4500$ & $4.5-6.8$ & $15(0.3 \%-0.5 \%)$ & CRF \\
\hline Italy & 58133509 & $5500-30000$ & $1.4-7.8$ & $70-150(0.2 \%-2.7 \%)$ & CRF, PC \\
\hline Spain & 46030109 & $15000-40000$ & $4.9-13.2$ & $150-450(0.4 \%-3.0 \%)$ & $\mathrm{CRF}^{39} 40$ \\
\hline Sweden & 9471174 & $3000-4000$ & $4.8-6.4$ & $80-135(2 \%-4.5 \%)$ & $\mathrm{CRF}^{41}$ \\
\hline The Netherlands & 16594107 & $3000-4500$ & $2.7-4.1$ & $16-120(0.4 \%-4.0 \%)$ & CRF \\
\hline Turkey & 73723000 & 27 700-34 000 & $4.6-7.0$ & $40(0.1 \%)$ & $\mathrm{CRF}^{42}$ \\
\hline UK & 61113210 & 25000 & 6.2 & $150-300(0.6 \%-1.2 \%)$ & $\mathrm{CRF}^{27} 4344$ \\
\hline Total & & $118500-208300$ & & $1173-1882(0.6 \%-1.6 \%)$ & \\
\hline \multicolumn{6}{|l|}{ Remaining EEA countries } \\
\hline Austria** & 8400000 & $500-3000$ & $0.9-5.5$ & $15(0.5 \%-3 \%)$ & \\
\hline Bulgaria†† & 7504868 & $2200-3400$ & $4.5-6.8$ & $11(0.3 \%-0.5 \%)$ & \\
\hline Cyprusł‡ & 854000 & $225-600$ & $4-11$ & $6-8(1.0 \%-3.6 \%)$ & \\
\hline Czech Republict† & 10327000 & $3100-4600$ & $4.5-6.8$ & $15(0.3 \%-0.5 \%)$ & \\
\hline Estoniat† & 1338000 & $400-600$ & $4.5-6.8$ & $2(0.3 \%-0.5 \%)$ & \\
\hline Finland§̧§ & 5399090 & $1700-2300$ & $4.8-6.4$ & $46-77(2.0 \%-4.5 \%)$ & \\
\hline Iceland§§ & 320000 & $100-135$ & $4.8-6.4$ & $3-5(2.2 \%-3.7 \%)$ & \\
\hline Irelandๆๆ & 4459300 & 1800 & 6 & $11-22(0.6 \%-1.2 \%)$ & 45 \\
\hline Latvia†† & 2263000 & $700-1000$ & $4.5-6.8$ & $3(0.3 \%-0.4 \%)$ & \\
\hline Liechtenstein ${ }^{* *}$ & 33717 & $2-12$ & $0.9-5.5$ & 0 & \\
\hline Lithuania†† & 3338700 & $1000-1500$ & $4.5-6.8$ & $5(0.3 \%-0.5 \%)$ & \\
\hline Luxembourg** & 465000 & $30-150$ & $1-5$ & $1(0.7 \%-3.3 \%)$ & \\
\hline Maltał‡ & 417608 & $110-300$ & $4-11$ & $3-4(1.0 \%-3.6 \%)$ & \\
\hline Norway§§ & 4920300 & $1600-2100$ & $4.8-6.2$ & $42-70(2.1 \%-4.5 \%)$ & \\
\hline Poland†† & 38038000 & $11300-17100$ & $4.5-6.8$ & $57(0.3 \%-0.5 \%)$ & \\
\hline Portugal ${ }^{* \star *}$ & 10605870 & $4100-9200$ & $5.9-13.2$ & $35-104(0.4 \%-2.5 \%)$ & \\
\hline Romania†† & 21462186 & $6400-9600$ & $4.5-6.8$ & $32(0.3 \%-0.5 \%)$ & \\
\hline Slovakia†† & 5411000 & $1600-2400$ & $4.5-6.8$ & $8(0.3 \%-0.5 \%)$ & \\
\hline Slovenia†† & 2010347 & $600-900$ & $4.5-6.8$ & $3(0.3 \%-0.5 \%)$ & \\
\hline $\begin{array}{l}\text { Total for countries under } \\
\text { EMA jurisdiction }\end{array}$ & 573545295 & $155967-268997$ & $4.1-7.1$ & $\begin{array}{l}1471-2324 \\
(0.5 \%-1.5 \%)\end{array}$ & \\
\hline
\end{tabular}

${ }^{*}$ Data obtained from CRFs or journal references.

†Prevalence of SLE was calculated from the information provided in the CRFs and calculated from the adult population (adults=66\% of the total population)) or journal references.

\#Figures obtained from the CRFs or journal references.

§Source of information is CRF, personal communication (PC) or journal reference.

ๆCroatia is not included, as it was not a member of EU or EEA (European Economic Area) when data were collected.

${ }^{\star *}$ Assumed similar to Germany.

††Assumed similar to Hungary.

$\ddagger \ddagger$ Assumed similar to Greece.

$\S \S$ Assumed similar to Sweden.

१П|Assumed similar to UK.

${ }_{* * \star}$ Assumed similar to Spain.

CRF, case report forms; EMA, European Medicines Agency; RTX, rituximab; SLE, systemic lupus erythematosus.

Details of treatment in patients with SLE

Among the RTX-treated patients, data on previous treatments were available for 95 patients of whom $82(86 \%)$ had previously received ISs and 13 had not. The previous ISs included CYX (46\%), mycophenolate mofetil $(40 \%)$, azathioprine $(35 \%)$, methotrexate $(12 \%)$ and other ISs (21\%, mainly ciclosporin A and intravenous Ig) (table 6). Most patients (69\%) had been treated with one or two different ISs prior to RTX, and $17 \%$ had been treated with three or more.
Previous treatments for the conventional IS-treated patients included azathioprine (28\%), CYX (26\%), mycophenolate mofetil $(17 \%)$, methotrexate $(10 \%)$ and other ISs $(6 \%)$. Many patients in this group (49\%) had not been previously treated with any ISs, and among those who had, the majority had one or two different ISs.

Two different dosing regimens for RTX were used: $375 \mathrm{mg} / \mathrm{m}^{2} \times 4 \quad(36 \%)$ and $1000 \mathrm{mg} \times 2 \quad(64 \%)$. Concomitant CYX was used in $40 \%$ of patients, most with LN (data not shown). At the time of RTX initiation, 
Table 4 Demographics of patients with SLE

\begin{tabular}{|c|c|c|c|c|c|}
\hline & RTX & $\mathbf{N}$ & IS & $\mathbf{N}$ & p Value \\
\hline Gender & 91\% Female & 103 & $89 \%$ Female & 72 & NS \\
\hline Age, mean $\pm S D$ & $36.5 \pm 12.0$ & 101 & $33.7 \pm 11.6$ & 72 & 0.124 \\
\hline \multirow[t]{3}{*}{ Smoking status } & $69 \%$ Never & 72 & $74 \%$ Never & 72 & NS \\
\hline & $14 \%$ Past & & $12 \%$ Past & & NS \\
\hline & $17 \%$ Current & & $14 \%$ Current & & NS \\
\hline \multirow[t]{6}{*}{ Ethnicity } & $93 \%$ Caucasian & 103 & $91 \%$ Caucasian & 72 & NS \\
\hline & $5 \%$ African-American & & 3\% Latino/South African & & \\
\hline & $1 \%$ Southeast Asian & & $3 \%$ Asian/Indian subcontinent & & \\
\hline & $1 \%$ Other & & $1 \%$ Southeast Asian & & \\
\hline & & & $1 \%$ Caribbean/Afro-Caribbean & & \\
\hline & & & $1 \%$ Other & & \\
\hline
\end{tabular}

Table 5 SLE disease characteristics for patients with SLE treated with RTX and conventional IS

\begin{tabular}{|c|c|c|c|c|c|}
\hline & RTX & $\mathbf{N}$ & IS & $\mathbf{N}$ & p Value \\
\hline Disease duration years, mean $\pm S D$ & $9.1 \pm 7.1$ & 101 & $4.1 \pm 6.6$ & 72 & $<0.0001$ \\
\hline Organ manifestation & (\%) & 103 & $(\%)$ & 72 & \\
\hline Renal (LN) & 58 & & 53 & & NS \\
\hline Musculoskeletal & 11 & & 22 & & 0.038 \\
\hline Haematological & 15 & & 11 & & NS \\
\hline Skin & 6 & & 6 & & NS \\
\hline CNS & 7 & & 3 & & NS \\
\hline Other & 3 & & 5 & & NS \\
\hline Reason for treatment & $(\%)$ & 103 & $(\%)$ & 72 & \\
\hline Controlling disease & 77 & & 44 & & $<0.0001$ \\
\hline Steroid-sparing & 1 & & 14 & & $<0.0001$ \\
\hline Both & 22 & & 42 & & 0.006 \\
\hline \multicolumn{6}{|l|}{ Disease activity } \\
\hline SLEDAI, mean \pm SD & $12.2 \pm 7.1$ & 102 & $9.4 \pm 7.0$ & 72 & 0.010 \\
\hline SLICC-DI, mean $\pm S D$ & $1.6 \pm 3.4$ & 96 & $0.6 \pm 1.0$ & 72 & 0.014 \\
\hline SLEDAI, LN vs & $14.6 \pm 6.2$ vs & 59 & $12.5 \pm 7.6$ vs & 38 & $<0.0001$ \\
\hline non-LN ${ }^{\star}$ & $9.0 \pm 6.9$ & 43 & $5.9 \pm 4.3$ & 34 & (within groups treatments) \\
\hline
\end{tabular}

*SLEDAI between groups, treatments: LN, NS; non-LN $p=0.029$.

CNS, central nervous system; IS, immunosuppressive; LN, lupus nephritis; NS, not significant; RTX, rituximab; SLE, systemic lupus erythematosus; SLICC, Systemic Lupus International Collaborating Clinics.

concomitant glucocorticoids were used in $68 \%$ of the patients. For patients treated with conventional IS, concomitant glucocorticoids were used in $94 \%$ of the patients. The most commonly initiated IS was mycophenolate mofetil $(45 \%)$, followed by azathioprine $(24 \%)$, CYX $(8 \%)$ and methotrexate $(6 \%)$.

\section{DISCUSSION}

We have performed a large European survey to assess the off-label use of RTX for the treatment of SLE, specifically investigating the extent to which rheumatologists use RTX compared with conventional ISs to treat patients with SLE. We have also looked at the characteristics of RTX-treated patients compared with patients treated conventionally.

One should keep in mind that treatment duration for RTX is poorly defined, because the biological effect may last from months to years. ${ }^{28}$ For this survey, we collected data for RTX treatment during a given time, and may therefore have missed a small number of patients given the treatment before that time and still benefiting from its effects.

Our study indicates that RTX is used off-label in European countries in $0.5 \%-1.5 \%$ of all patients with SLE. Because this study was limited to rheumatology specialty centres, the true usage of RTX may be somewhat higher but likely to remain in the same single-digit percentage range, indicating that the use of RTX is restrictive. Significant heterogeneity in the off-label use of RTX was also observed. In some countries, off-label use is discouraged through regulatory or reimbursement mechanisms rendering use impossible in practical terms. In other European countries, off-label use can be both permitted and fully reimbursed when motivated by the clinical situation. Such is the case in Sweden, where this 
Table 6 Previous conventional immunosuppressives

\begin{tabular}{|c|c|c|c|c|c|}
\hline Previous ISs & $\begin{array}{l}\text { RTX } \\
\text { (\%) }\end{array}$ & $\mathrm{N}=95$ & $\begin{array}{l}\text { IS } \\
\text { (\%) }\end{array}$ & $\mathrm{N}=72$ & p Value \\
\hline Cyclophosphamide & 46 & & 26 & & 0.009 \\
\hline Mycophenolate mofetil & 40 & & 17 & & 0.001 \\
\hline Azathioprine & 35 & & 28 & & NS \\
\hline Methotrexate & 12 & & 10 & & NS \\
\hline Other & 21 & & 6 & & 0.005 \\
\hline No ISs & 14 & & 49 & & $<0.0001$ \\
\hline
\end{tabular}

Number of previous

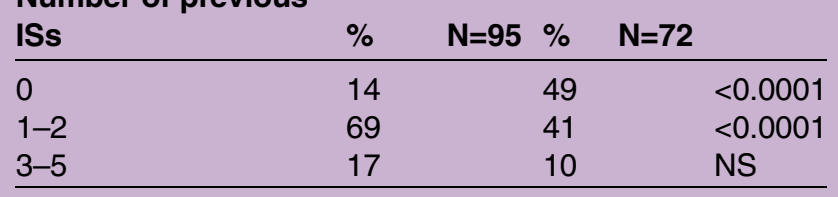

IS, immunosuppressive; NS, not significant; RTX, rituximab.

report originated and where the off-label use of RTX in SLE was the highest among the countries surveyed (table 3). However, this may change, in part because RTX is now recommended in both European League Against Rheumatism (EULAR) and ACR guidelines for refractory $\mathrm{LN}$, and in part because less expensive biosimilars for RTX may become available.

A comparison between patients treated with RTX and those treated with conventional ISs was made to analyse similarities and differences between the two groups. Patients treated with RTX were on average somewhat older and had longer disease duration. The characteristics of patients treated with RTX in this study suggest a clear focus on patients with high disease activity (table 5). As measured by the SLEDAI, where 10 or greater is usually considered 'severe' disease, the average disease activity of the RTX-treated patients was 12.2 compared with 9.4 in the control group. For the RTX group, the average SLICC-DI was 1.6 compared with 0.6 for the control group. Longitudinal studies have demonstrated that even a single point on this damage scale associates with significantly lower quality of life, higher rates of flares and end-organ complications, as well as shorter life expectancy ${ }^{29-31}$ Both findings support the hypothesis that RTX is chosen for patients with more severe lupus.

The organ systems for which RTX and the conventional agents were chosen did not differ as much as might have been expected. LN was present in about half the patients in each group (table 5). This is the organ manifestation by far the most studied and for which the evidence is most clear that aggressive immunosuppressive or immunomodulatory treatment can be beneficial. It has been shown for early LN to have a substantial corticoid sparing effect. ${ }^{32}$ Musculoskeletal manifestations were under-represented among patients treated with RTX compared with those treated with conventional ISs. This may be explained by the fact that one of the ISs used, methotrexate, is by far the most widely used antirheumatic agent for patients with inflammatory arthritides. Therefore, rheumatologists may be more inclined to use this drug for patients with musculoskeletal lupus. Also, the use of RTX for musculoskeletal SLE was strongly discouraged by the negative results of the EXPLORER trial. ${ }^{33}$ In contrast to musculoskeletal lupus, there was a small numerical over-representation of haematological manifestations (thrombocytopenia and/ or haemolytic anaemia) in patients treated with RTX, which may be explained by the strong link between haematological lupus and autoantibodies and the impression that autoantibody-mediated lupus manifestations may be particularly susceptible for RTX treatment.

The proportion of patients with predominant mucocutaneous lupus was strikingly lower than that would be expected based on the prevalence of such manifestations in the overall SLE population, suggesting that neither immunosuppressive is perceived as effective for mucocutaneous lupus. Indeed, there is only limited evidence for their efficacy.

While RTX was typically identified by the clinician as a treatment to control disease activity, conventional ISs were used primarily for corticosteroid-sparing purposes, consistent with recent emphasis in lupus therapeutics on minimising corticosteroid exposure ${ }^{34}$ (table 5). In this group, the start of conventional IS treatment was often accompanied by high glucocorticoid dosages. Although not specifically queried, we believe this reflects the clinician's concern that conventional ISs are slow-acting agents, requiring several months or more to achieve disease control. Highly active SLE must therefore initially be controlled through the addition of moderatehigh glucocorticoid dosages ('bridging therapy').

Patients treated with RTX had a history of more use of conventional ISs than the control group. This supports the view that RTX is used after conventional therapeutic options have been exhausted (table 6).

This study was based on various sources of information, and the hierarchy of evidence was assigned in the following order: registry-based datasets, CRFs submitted by the participating investigators, published data from the literature and responses to specific queries. Each of these sources carries some limitations. Common to all is that data were collected, collated and analysed retrospectively.

The overall methodology is, in large part, 'sensible extrapolation'. Thus, most of the primary data reflect the situation in individual centres, regions, or, in some instances, countries. From these data, countrywide estimates of RTX use for SLE were derived, which-except for the few countries that provided countrywide dataentailed extrapolation. In order to make this as reliable as possible, additional support was taken from the literature and from direct contact with investigators. Estimates obtained for some of the EU countries were extrapolated to countries that were not represented in the datasets for this study. Countries used for this extrapolation were chosen based on cultural and geographical similarities. Finally, the results obtained may not be applicable 
to all countries, as most patients in the study are Caucasian.

Another significant limitation was the focus on the rheumatology specialty. Because patients with more severe SLE are usually treated by rheumatology specialists, our initial approach seemed reasonable. Since RTX has been proposed in the literature as a potential alternative in the treatment of $\mathrm{LN}$, and since $\mathrm{LN}$ can exist almost completely in isolation in the individual patient (ie, without other significant lupus manifestations), it is conceivable that some patients with LN are treated with RTX solely by nephrologists. Therefore, it may be more accurate to say that this study estimates the use of RTX for SLE within the rheumatology specialty. The possibility that other specialists (eg, dermatologists, neurologists, haematologists) would treat patients with SLE with RTX without the involvement of a rheumatologist is more remote.

In summary, this study on the off-label use of RTX in SLE has provided a number of insights into hitherto underexplored lupus therapeutics. The pattern of RTX use suggests that it is limited to specialised, tertiary care centres. The fact that currently only a relatively small proportion of patients are treated with RTX, and that these patients in general have been treated with multiple immunosuppressives previously, suggests that RTX is chosen only for patients for whom all reasonable conventional options have been exhausted. Moreover, RTX is used in patients with high disease activity and a significant burden of SLE-related damage. As such, the current usage of RTX in SLE may be considered conservative, representing an appropriately used medication of last resort for those with the highest medical need within the larger patient population with SLE.

\section{Author affiliations}

${ }^{1}$ Unit of Clinical Therapy Research, Inflammatory Diseases, Department of Medicine, Karolinska Institutet, Karolinska University Hospital, Stockholm, Sweden

${ }^{2}$ Joint Academic Rheumatology Program and 4th Department of Medicine, Medical School, National and Kapodestrian University of Athens, Attikon University Hospital, Athens, Greece

${ }^{3}$ Department of Rheumatology, Amsterdam Rheumatology and Immunology Center, Amsterdam, The Netherlands

${ }^{4}$ Unit of Autoimmune Diseases, Hospital San Cecilio, Granada, Spain

${ }^{5}$ Autoimmune Systemic Diseases Unit, Internal Medicine Department, Hospital Universitario Central de Asturias, Oviedo, Spain

${ }^{6}$ Internal Medicine Department, University Hospital Sant Joan de Reus, Rovira i Virgili University (URV)-IISPV, Reus, Spain

${ }^{7}$ Pasaje Nueva Victoria, 2, 2do C, Jaén, Spain

${ }^{8}$ Rheumatology Unit, Department of Medicine, University of Padova, Padova, Italy

${ }^{9}$ Department of Medicine/Rheumatology and Clinical Immunology, Charite Universitaetsmedizin Berlin, Berlin, Germany

${ }^{10}$ Autoimmune Diseases Research Unit, Department of Internal Medicine,

BioCruces Health Research Institute, Cruces University Hospital, University of the Basque Country, Barakaldo, Spain

${ }^{11}$ Institute of Rheumatology and Affine Sciences (IRSA), Catholic University of the Sacred Heart, Rome, Italy

${ }^{12}$ Service de Rhumatologie, Cliniques Universitaires Saint-Luc, Pôle de

Pathologies Rhumatismales Inflammatoires et Systémiques, Université Catholique de Louvain, Brussels, Belgium

${ }^{13}$ Department of Rheumatology, C1-41, Leiden University Medical Center, Leiden, The Netherlands
${ }^{14}$ Division of Rheumatology, Department of Internal Medicine, Istanbul Medical Faculty, Istanbul University, Istanbul, Turkey

${ }^{15}$ University College London, The Rayne Building, London, UK

${ }^{16}$ Rheumatology Unit, San Camillo Hospital, Rome, Italy

${ }^{17}$ Copenhagen Lupus and Vasculitis Clinic, Center for Rheumatology and Spine Diseases, University of Copenhagen, Rigshospitalet, Copenhagen, Denmark

${ }^{18}$ Internal Department, Universitary 'Virgen de las Nieves' Hospital, Granada, Spain

${ }^{19}$ Department of Rheumatology, Faculty of Medicine, Albert Szent-Györgyi Health Centre, University of Szeged, Szeged, Hungary

${ }^{20}$ Rhumatologie Responsable de I'Unité de Recherche Clinique, Hôpitaux Universitaire Paris-Sud, Université Paris-Sud, INSERM U1184, Paris, France

${ }^{21}$ Rheumatology Unit, Pisa, Italy

${ }^{22}$ Rheumatology Clinic, Skåne University Hospital, Lund, Sweden

${ }^{23}$ Internal Medicine Department, Hospital de Sabadell, Universitat Autonoma de Barcelona, Catalunya, Spain

${ }^{24}$ Department of Autoimmune Diseases, ICMiD, Josep Font Autoimmune Lab, CELLEX-IDIBAPS, Barcelona, Spain

${ }^{25}$ Carrer de les Sabateres, 9-1, Alaró, Islas Baleares, Spain

${ }^{26}$ Unidad de Enfermedades Autoinmunes Sistémicas, Hospital Universitario

Miguel Servet de Zaragoza, Paseo Isabel la Católica, Zaragoza, Spain

${ }^{27}$ Department of Internal Medicine, Inmunopathological and Autoimmune Area, Hospital Universitario y Politecnico La Fe, Valencia, Spain

${ }^{28}$ UOC Reumatologia, Ospedale San Camillo, Circonvallazione Gianicolense n. 87, Roma, Italy

${ }^{29}$ Department of Sperimental and Clinical Medicine, University of Florence,

Firenze, Italy

${ }^{30}$ Department of Rheumatology, Institute of Medicine, University of Debrecen, Debrecen, Hungary

${ }^{31}$ Amsterdam Rheumatology and Immunology Center (ARC), VU University Medical Center, Amsterdam, The Netherlands

${ }^{32}$ Rheumatology Clinic, Karolinska University Hospital, Stockholm, Sweden

${ }^{33}$ Amsterdam Rheumatology and Immunology Center ARC, AMC mail F4-105, Amsterdam, The Netherlands

Contributors MRA had the lead role in drafting of the manuscript and its final approval for submission. All authors participated in critically reviewing the manuscript. All authors, except MRA, contributed with data from their respective centre/region/country and took part in analyses and discussions regarding these data. RvV was Steering Committee Chair in the IRBIS registry and responsible investigator of the survey reported here. He supported the statistical analyses and interpretations of the data. He also discussed and reviewed the manuscript critically and gave his final approval for submission of the manuscript.

Funding IB: speaker fees from MSD and Lilly Netherlands. TD: study support by Roche, UCB and Sanofi; honoraria for scientific advice from Roche, Chugai, Sanofi, Eli Lilly and UCB. FAH and MI: research grants from Roche. DI: acted as an adviser to a number of companies in the past 5 years, including GlaxoSmithKline, Eli Lilly and Roche; the honoraria offered are passed on to a local arthritis charity. RvV: research support and grants. For performing the analyses reported here, which were requested by the European Medicines Agency (EMA), the authors received an unrestricted grant from Roche. Other: AbbVie, Amgen, BMS, GSK, Pfizer, UCB. Consultancy, honoraria: AbbVie, Biotest, BMS, Celgene, Crescendo, GSK, Janssen, Lilly, Merck, Novartis, Pfizer, Roche, UCB and Vertex.

Competing interests LZC: BIOGEAS study group.

Ethics approval Approvals were obtained in each country where needed.

Provenance and peer review Not commissioned; externally peer reviewed.

Data sharing statement No additional data are available.

Open Access This is an Open Access article distributed in accordance with the Creative Commons Attribution Non Commercial (CC BY-NC 4.0) license, which permits others to distribute, remix, adapt, build upon this work noncommercially, and license their derivative works on different terms, provided the original work is properly cited and the use is non-commercial. See: http:// creativecommons.org/licenses/by-nc/4.0/ 


\section{REFERENCES}

1. Györi N, Tani C, Mosca M. Advances in therapies for systemic lupus erythematosus. In: RF van Vollenhoven, ed. Clinical therapy research in the inflammatory diseases. World Scientific Press, 2015.

2. Zen M, laccarino L, Gatto $M$, et al. Prolonged remission in Caucasian patients with SLE: prevalence and outcomes. Ann Rheum Dis 2015;74:2117-22.

3. Furie R, Petri M, Zamani O, et al. A phase III, randomized, placebo-controlled study of belimumab, a monoclonal antibody that inhibits B lymphocyte stimulator, in patients with systemic lupus erythematosus. Arthritis Rheum 2011;63:3918-30.

4. Navarra SV, Guzmán RM, Gallacher AE, et al. Efficacy and safety of belimumab in patients with active systemic lupus erythematosus: a randomised, placebo-controlled, phase 3 trial. Lancet 2011;377:721-31.

5. Leandro MJ, Cooper N, Cambridge G, et al. Bone marrow B-lineage cells in patients with rheumatoid arthritis following rituximab therapy. Rheumatology (Oxford) 2007;46:29-36

6. Jones RB, Tervaert JW, Hauser T, et al. Rituximab versus cyclophosphamide in ANCA-associated renal vasculitis. $N$ Engl J Med 2010;363:211-20.

7. Stone $\mathrm{JH}$, Merkel PA, Spiera $\mathrm{R}$, et al. Rituximab versus cyclophosphamide for ANCA-associated vasculitis. N Engl J Med 2010;363:221-32

8. Merrill JT, Neuwelt CM, Wallace DJ, et al. Efficacy and safety of rituximab in moderately-to-severely active systemic lupus erythematosus: the randomized, double-blind, phase II/III systemic lupus erythematosus evaluation of rituximab trial. Arthritis Rheum 2010;62:222-33.

9. Rovin BH, Furie R, Latinis K, et al. Efficacy and safety of rituximab in patients with active proliferative lupus nephritis: the Lupus Nephritis Assessment with Rituximab study. Arthritis Rheum 2012:64:1215-26.

10. Leandro MJ, Edwards JC, Cambridge G, et al. An open study of B lymphocyte depletion in systemic lupus erythematosus. Arthritis Rheum 2002:46:2673-7.

11. Looney RJ, Anolik JH, Campbell D, et al. B cell depletion as a novel treatment for systemic lupus erythematosus: a phase I/II dose-escalation trial of rituximab. Arthritis Rheum 2004:50: 2580-9.

12. Gottenberg JE, Guillevin L, Lambotte $\mathrm{O}$, et al. Tolerance and shor term efficacy of rituximab in 43 patients with systemic autoimmune diseases. Ann Rheum Dis 2005;64:913-20.

13. Gunnarsson I, Sundelin B, Jónsdóttir T, et al. Histopathologic and clinical outcome of rituximab treatment in patients with cyclophosphamide-resistant proliferative lupus nephritis. Arthritis Rheum 2007;56:1263-72.

14. Jónsdóttir T, Gunnarsson I, Risselada A, et al. Treatment of refractory SLE with rituximab plus cyclophosphamide: clinical effects, serological changes, and predictors of response. Ann Rheum Dis 2008;67:330-4.

15. Boletis JN, Marinaki S, Skalioti C et al. Rituximab and mycophenolate mofetil for relapsing proliferative lupus nephritis: a long-term prospective study. Nephrol Dial Transplant 2009;24:2157-60.

16. Li EK, Tam LS, Zhu TY, et al. Is combination rituximab with cyclophosphamide better than rituximab alone in the treatment of lupus nephritis? Rheumatology (Oxford) 2009;48:892-8.

17. Melander $C$, Sallée $M$, Trolliet $P$, et al. Rituximab in severe lupus nephritis: early B-cell depletion affects long-term renal outcome. Clin J Am Soc Nephrol 2009;4:579-87.

18. Roccatello D, Sciascia S, Rossi D, et al. Intensive short-term treatment with rituximab, cyclophosphamide and methylprednisolone pulses induces remission in severe cases of SLE with nephritis and avoids further immunosuppressive maintenance therapy. Nephrol Dial Transplant 2011;26:3987-92.

19. laccarino L, Bartoloni E, Carli L, et al. Efficacy and safety of off-label use of rituximab in refractory lupus: data from the Italian Multicentre Registry. Clin Exp Rheumatol 2015;33:449-56.

20. Tanaka Y, Takeuchi T, Miyasaka N, et al. Efficacy and safety of rituximab in Japanese patients with systemic lupus erythematosus and lupus nephritis who are refractory to conventional therapy. Mod Rheumatol 2016;26:80-6.

21. van Vollenhoven RF, Askling J. Rheumatoid arthritis registries in Sweden. Clin Exp Rheumatol 2005;23(Suppl 39): S195-200.

22. Silman A, Symmons D, Scott DG, et al. British Society for Rheumatology Biologics Register. Ann Rheum Dis 2003;62(Supp 2):ii28-9.
23. Hetland ML. DANBIO: a nationwide registry of biological therapies in Denmark. Clin Exp Rheumatol 2005;23(Suppl 39):S205-7.

24. Witt M, Grunke M, Proft F, et al. Clinical outcomes and safety of rituximab treatment for patients with systemic lupus erythematosus (SLE) - results from a nationwide cohort in Germany (GRAID). Lupus 2013;22:1142-9.

25. Fessel WJ. Systemic lupus erythematosus in the community. Incidence, prevalence, outcome, and first symptoms; the high prevalence in black women. Arch Intern Med 1974;134:1027-35.

26. Samanta A, Roy S, Feehally J, et al. The prevalence of diagnosed systemic lupus erythematosus in whites and Indian Asian immigrants in Leicester city, UK. Br J Rheumatol 1992;31:679-82.

27. Hopkinson ND, Doherty M, Powell RJ. Clinical features and race-specific incidence/prevalence rates of systemic lupus erythematosus in a geographically complete cohort of patients. Ann Rheum Dis 1994:53:675-80.

28. Lu TY, Jonsdottir T, van Vollenhoven RF, et al. Prolonged B-cell depletion following rituximab therapy in systemic lupus erythematosus: a report of two cases. Ann Rheum Dis 2008;67:1493-4.

29. Wang C, Mayo NE, Fortin PR. The relationship between health related quality of life and disease activity and damage in systemic lupus erythematosus. The Journal of rheumatology 2001;28:525-32.

30. Jönsen A, Bengtsson AA, Nived O, et al. Outcome of neuropsychiatric systemic lupus erythematosus within a defined Swedish population: increased morbidity but low mortality. Rheumatology (Oxford) 2002;41:1308-12.

31. Pettersson S, Lövgren M, Eriksson LE, et al. An exploration of patient-reported symptoms in systemic lupus erythematosus and the relationship to health-related quality of life. Scand J Rheumatol 2012;41:383-90.

32. Condon MB, Ashby D, Pepper RJ, et al. Prospective observational single-centre cohort study to evaluate the effectiveness of treating lupus nephritis with rituximab and mycophenolate mofetil but no oral steroids. Ann Rheum Dis 2013;72:1280-6.

33. Merrill J, Buyon J, Furie R, et al. Assessment of flares in lupus patients enrolled in a phase II/III study of rituximab (EXPLORER). Lupus 2011;20:709-16.

34. van Vollenhoven RF, Mosca M, Bertsias G, et al. Treat-to-target in systemic lupus erythematosus: recommendations from an international task force. Ann Rheum Dis 2014;73:958-67.

35. Voss A, Green A, Junker P. Systemic lupus erythematosus in Denmark: clinical and epidemiological characterization of a county-based cohort. Scand J Rheumatol 1998;27:98-105.

36. Fischer-Betz R, Wessel E, Richter J, et al. [Lupus in Germany: analysis within the German lupus self-help organization (LULA)]. Z Rheumatol 2005;64:111-22.

37. Alamanos Y, Voulgari PV, Siozos C, et al. Epidemiology of systemic lupus erythematosus in northwest Greece 1982-2001. J Rheumatol 2003;30:731-5.

38. Anagnostopoulos I, Zinzaras E, Alexiou I, et al. The prevalence of rheumatic diseases in central Greece: a population survey. BMC Musculoskelet Disord 2010;11:98.

39. López P, Mozo L, Gutiérrez C, et al. Epidemiology of systemic lupus erythematosus in a northern Spanish population: gender and age influence on immunological features. Lupus 2003;12:860-5.

40. EPISER. Prevalencia de enfermedades reumáticas en la población espanola. http://www.ser.es/investigacion/Proyectos/Episer/Episer. php

41. Ståhl-Hallengren $\mathrm{C}$, Jönsen $\mathrm{A}$, Nived $\mathrm{O}$, et al. Incidence studies of systemic lupus erythematosus in Southern Sweden: increasing age, decreasing frequency of renal manifestations and good prognosis. $J$ Rheumatol 2000;27:685-91.

42. Cakir N, Pamuk ÖN, Derviş E, et al. The prevalences of some rheumatic diseases in western Turkey: Havsa study. Rheumatol Int 2012;32:895-908.

43. Hopkinson ND, Doherty M, Powell RJ. The prevalence and incidence of systemic lupus erythematosus in Nottingham, UK, 1989-1990. Br J Rheumatol 1993;32:110-15.

44. Johnson AE, Gordon C, Palmer RG, et al. The prevalence and incidence of systemic lupus erythematosus in Birmingham, England. Relationship to ethnicity and country of birth. Arthritis Rheum 1995:38:551-8.

45. Gourley IS, Patterson CC, Bell AL. The prevalence of systemic lupus erythematosus in Northern Ireland. Lupus 1997;6:399-403. 